\title{
NUMERICAL MODELING OF USING PILES TO RESIST HEAVE I] EXPANSIVE SOIL
}

Tarek N. Salem, Nagwa R. El-sakhawy, Rehab A. E. El-sayed

\begin{abstract}
Expansive soil causes considerable damages to structures all over the world. It is necessary that when des foundations resting over expansive soils, the expected heave of foundations should be calculated and cons accounted for. Piles foundations are an alternative for the cases of highly expansive soils extending to dee! the foundations, especially in light weight structures. This paper presents numerical modeling of piles in es The finite element software (ADINA) is used in the modeling, Cam-Clay soil model representing the expan: a verification of the proposed numerical model, a well documented case study of piles constructed in expal used. The case of TRACON building located at Denver International Airport (DIA), Denver, Colorado, in whi behavior is tracked and measured for six years continuously. Results showed good agreement between the values and the reproduced numerical results. The verified numerical model is used in the analysis of cases piles, belled piles, and pile groups. Results showed that pile groups are more effective than belled piles in total heave than single piles
\end{abstract}

